\title{
RESULTS OF THE ULTRAMICROSCOPIC RESEARCH OF ADENOID VEGETATIONS ACCOMPANIED BY THE PATHOLOGIES OF NASAL CAVITY AND PARANASAL SINUSES IN ADULTS
}

DOI: 10.36740/WLek202008107

\author{
Inna A. Plakhtiienko ${ }^{1}$, Yevhen V. Smiianov ${ }^{1}$, Vladyslav A. Smiianov ${ }^{1}$, Volodymyr V. Savchenko ${ }^{2}$ \\ 'SUMY STATE UNIVERSITY, SUMY, UKRAINE \\ 2REGIONAL DENTAL CLINIC, SUMY, UKRAINE
}

\begin{abstract}
The aim: Grounding on the electronic microscopy of PT make conclusions about the tonsil activity in adults depending on the accompanied pathology of nose and PS. Materials and methods:Ultramicroscopic examination of 111 patients with PT hypertrophy aged 18-55 was done. Depending on the nose and PS pathology (inflammatory, non-inflammatory) patients'PS biopsic materials were distributed into 2 groups: 58 cases on inflammatory and 53 on non-inflammatory background. The control group consisted of 24 patients aged 18 without nose and PS pathology. The images of ultrathin PT sections were received with the help of transmission electronic microscope PEM - 125 with digital camera (SELMI, Sumy).

Results: Great variations in PT cell condition, depending on the pathology were distinguished. Features of the adenoiditis in inflammatory and non-inflammatory diseases of nose and PS were proved.

Conclusions: 1. PT ultra-microscopy in control group shows great activity of lymphocytes and high energy exchange of cells, with prevailing B-lymphocyte population. 2. The complex of PT ultra structural changes while nose and PS inflammatory diseases shows the activation of immune reaction in competent cells with T-lymphocyte increase in patients older than 25 , which witnesses chronic inflammation.

3. In group with nose and PT non-inflammatory diseases, activity of PT B-lymphocytes is unchanged accompanied by the T-lymphocytes growth, which is also characteristic for chronic inflammation
\end{abstract}

KEY WORDS: pharyngeal tonsil hypertrophy, adenoiditis

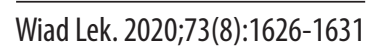

\section{INTRODUCTION}

Today, in pediatric otolaryngology the effect of hypertrophy and inflammation of the pharyngeal tonsil (PT) on the condition of the nasal cavity, auditory tube and pharynx $[1,2,3]$ is well studied, rational regimens of conservative and surgical treatment have been proposed, and the state of local and general immunity [4] has been taken into account. Though, in the literature, there is practically no data on the frequency of hypertrophy of PT and its influence on the status of ENT organs in adults. Considering that the nasopharyngeal cavity is not available for examination in all cases, even with posterior rhinoscopy, the diagnosis of hypertrophy of PT and adenoiditis remains a relevant problem in adult otolaryngology [5].

In the pathogenesis of inflammatory diseases of the nasal cavity and paranasal sinuses, the leading link is a decrease in the level of local resistance. Perhaps this explains PT hyperplasia in adults by the type of compensatory response of local immunity factor deficiency [6]. According to modern views, all structures of the lymphoid ring of the pharynx, as well as the lymphoid elements of the mucous membrane of the upper respiratory tract are closely linked morphologically and, of course, pathophysiologically. The data prove that there is an exchange of immunocytes between lymphoid pharynx formations. Removal or destruction of one of the structures of the lymph-pharyngeal ring leads to compensatory changes in other formations, which creates the conditions for a particular clinical course of diseases in the mucous membrane of the upper respiratory tract $[7,8]$. However, in adulthood, it is difficult to establish the level of activity of PT for the reason that muconasal immunity is already formed and PT, in most cases, undergoes involution and is not the main source of SIgA [9]. The study of the ultramicroscopic picture of the organ makes it possible to evaluate with confidence the activity of lymphoid cells of the tonsils.

\section{THE AIM}

On the basis of electron microscopy of the pharyngeal tonsil to conclude about the state of activity of this organ in adults, depending on concomitant pathology of the nose and paranasal sinuses.

\section{MATERIALS AND METHODS}

This research was approved by the Ethics Committee of Sumy State University, Sumy, Ukraine. Research was conducted keeping to the main issues of the Convention of the Council of Europe on Human Rights and Biomedicine of 
Declaration of Helsinki of the World Medical Association on the ethical principles of conducting medical research involving human beings (1975, with further amendments, including version of 2000) and Order of Ukrainian Ministry of Health № 690 on 23.09.2009.

The study material was biopsy preparations of PT adults of patients of different age groups operated on for inflammatory and non-inflammatory (deformation of the nasal septum, hypertrophy of the lower nasal conch) of diseases of the nose and paranasal sinuses.

Depending on the concomitant pathology of the nasal cavity and NPS (inflammatory and non-inflammatory) biopsy preparations of PT patients (withdrawn immediately after surgery) were divided into 2 main study groups.

The first core group (AID) included 58 cases of the study of PT adults in the background of inflammatory diseases of the nose and NPS. The first main group (AID) consisted of the following subgroups: 1) AID1 - 19 cases of the study of PT adults in the age group of 18-25 years; 2 ) AID2 - 21 case studies of PT adults in the age range of $26-45$ years; 3 ) AID3 - 18 cases of PT study of adults aged 46 years and over.

The second main group (AND) consisted of 53 cases of the study of PT on the background of non-inflammatory diseases of the nose and NPS. The second major group (AND) consisted of the following subgroups, depending on the age period ( $18-25$ years, $26-45$ years, and 46 and more years) of the patients examined: ND1 - 16 cases, AND2 - 19 cases and AND3 - 18 cases in accordance.

The control group (CG) was the autopsy biopsy of the PT of adults who died suddenly from severe gastrointestinal bleeding. The control group (CG) was subdivided into three subgroups, according to the age range of patients (18-25 years, 26-45 years, and 46 and older): CG1 - 5 study cases, CG2 - 11 cases, and CG3 - 8 cases.

For electron microscopic examination with PT, a piece of $1 \mathrm{~mm} 3$ was collected and fixed in a solution of glutaraldehyde. Thereafter, postfixation in $1 \%$ osmium solution and pouring of the material into a mixture of epon-araldite resins took place. Subsequently, ultrathin sections were obtained followed by contrast with lead citrate and uranyl acetate. Images were obtained using a PEM-125 transmission electron microscope with a digital video camera (SELMI, Sumy).

Statistical processing of the received data was made in the programs Exel and STATISTICA 6.0. Data rows were checked for normality with the help of Shapiro-Wilk statistical criteria (small sample) and Kolmohorov-Smirnov (large sample). During the comparison of the rows, the Student and Wilkokson criteria for the non-paired were used.

\section{RESULTS}

\section{ELECTRON MICROSCOPY OF THE PHARYNGEAL} TONSIL OF THE PATIENTS IN THE CONTROL GROUP Some differences in the ultramicroscopic picture of PT in patients of groups CG1, CG2 and CG3 were revealed. Electron microscopy of CG1 lymphocytes from patients in the

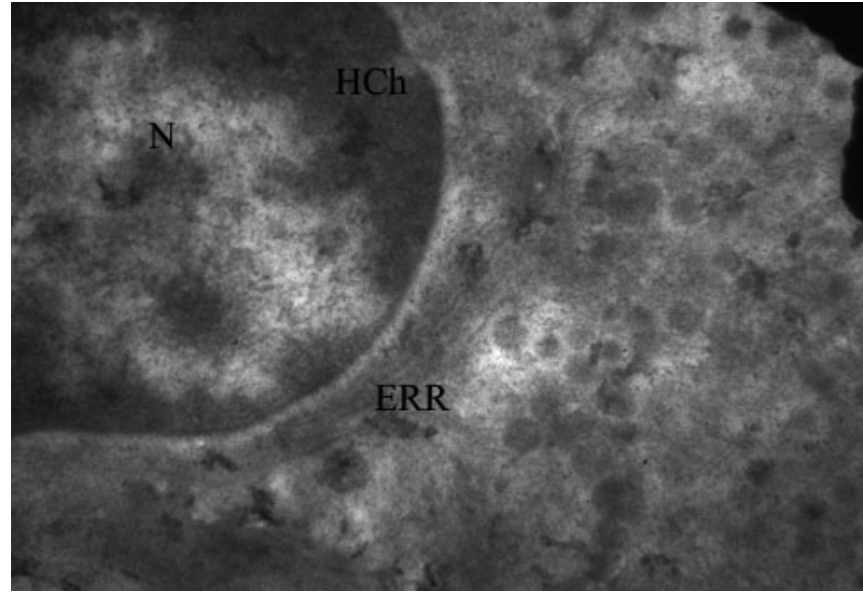

Fig. 1. B-lymphocyte ultra-structure in the patient of KG1 group. Cell's nucleus (N) has significant quantity of peripherally placed heterochromatin (HCh). Endoplasmic rough reticulum (ERR) with fixed ribosomes is located near the nucleus. Coll. X 10800

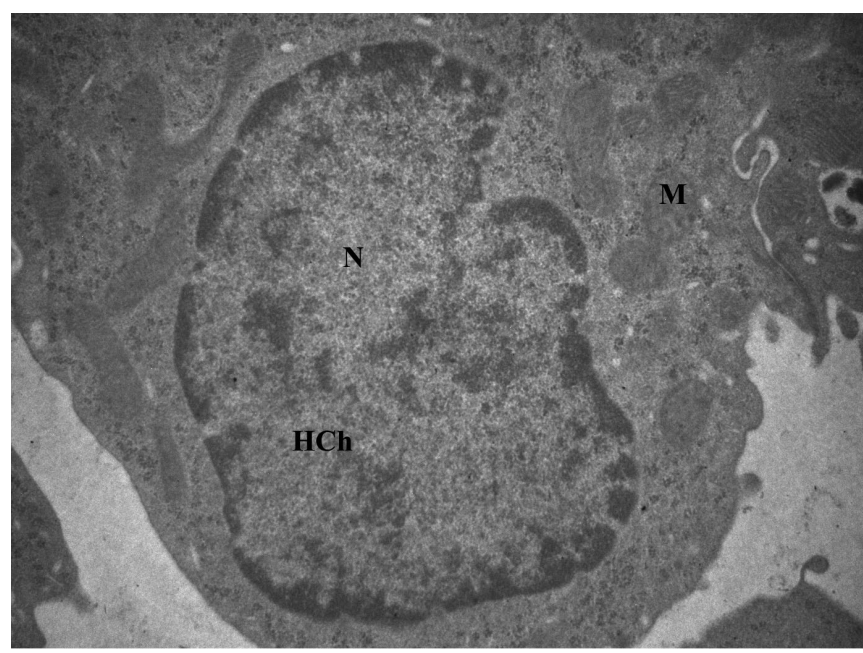

Fig. 2. B-lymphocyte ultra-structure in the patient of AID1 group. Decrease of heterochromatin $(\mathrm{HCh})$ in the nucleus $(\mathrm{N})$, absence of the cisterns of endoplasmic rough network, a part of mitochondria $(M)$ with destroyed cristae is observed. Coll. X 5400

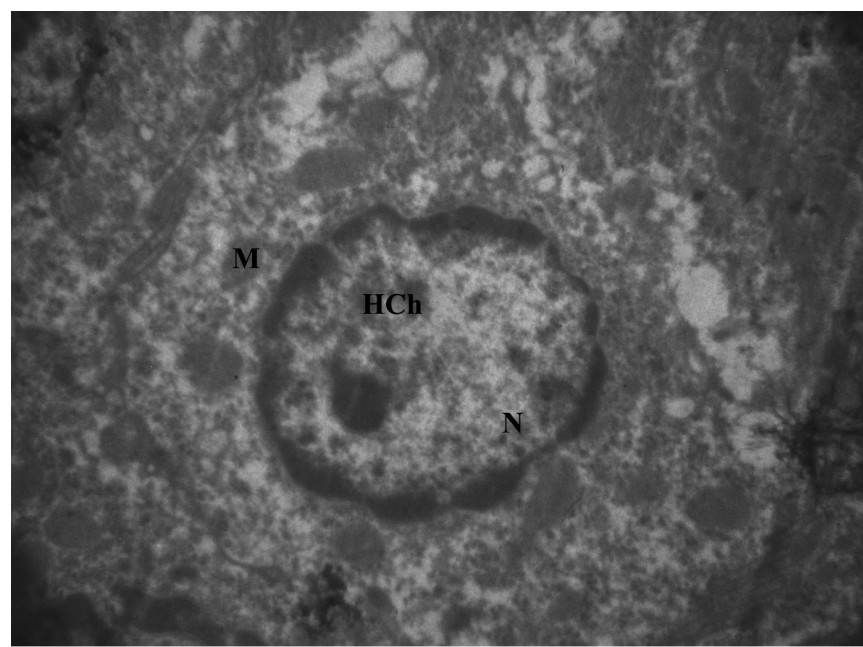

Fig. 3. B-lymphocyte ultra-structure of the patient of AND2 group. Aggregation of heterochromatin (HCh) is observed in the nucleus (N). A part of mitochondria (M) has homogeneous electron-dense matrix. Cytoplasm is partially vacuolated. Coll. X 4500 
control group is represented by $\mathrm{T}$ - and $\mathrm{B}$-cell populations. In group CG1, the number of B- over T-lymphocytes is predominant, but there is a slight increase in the number of T-lymphocytes in the studied tissue in the age groups CG2 and CG3. In practically healthy individuals 18 - 25 years (CG1), the nucleus of B-lymphocytes is mainly hyperchromic, with a small amount of peripherally located heterochromatin, which indicates the activation of transcription processes (Fig. 1). The amount of heterochromatin in the nuclei of cells of groups CG2 and CG3 increases, which indicates a decrease in metabolic processes in the cell.

In the cytoplasm of B-lymphocytes of patients of the control group, CG1 organelles are occupied, occupying most of the intracellular space. Mitochondria with well-developed crystals are located in the nucleus space. The mitochondrial matrix is electron-dense. It should be noted that the number of organelles decreases with age. The number of mitochondria in the CG3 group was found to be significantly reduced, their size reduced, crystalline deformation and mitochondrial matrix enlightenment were visualized, indicating that energy processes in the cell were reduced.

In practically healthy subjects 18 - 25 years (CG1) on the opposite pole of the cell is a well-pronounced granular endoplasmic reticulum, on the surface of which are fixed ribosomes. The number of ribosomes decreases with age, especially in patients of the CG3 group.

It was found that about $25 \%$ of the B-lymphocytes of the tonsils of patients of group CG1 can be morphologically attributed to activated cells. Whereas in the CG2 group the percentage of activated B-lymphocytes decreases to $10 \%$, and in the CG3 group there are single activated cells.

T-lymphocytes of the pharyngeal tonsils of patients of the control group G1 make up a smaller part of the population of lymphocytes. A distinctive feature of this subpopulation of lymphocytes is the presence of numerous free ribosomes in the cytoplasm. In addition, T-lymphocytes contain many mitochondria, well-developed crystals, and an electro-dense matrix. It should be noted that the population of T-lymphocytes has the same involution changes that are characteristic of B-lymphocytes. The content of heterochromatin in nuclei increases; mitochondria have deformed crystals and electron-transparent matrix. There is a significant decrease in the number of free ribosomes, especially in patients of the CG3 group.

\section{ELECTRON MICROSCOPY OF THE PHARYNGEAL TONSIL OF ADULTS WITH INFLAMMATORY DISEASES OF THE NOSE AND NPS}

There is an increase in the ratio of B-lymphocytes in individuals of the AID1 (Fig. 2) group compared with patients in the control group. The ultramicroscopic picture of patients of the AID1 group is characterized by a decrease in the amount of heterochromatin and an expansion of the perinuclear space. However, in the pharyngeal tonsils of patients of the AID2 group, there was a slight increase in lymphocytes, which indicates an age-related decrease in the barrier function of the tonsils. The amount of het- erochromatin in the nuclei of the cells decreases slightly, while the perinuclear space is expanded. Vacuolation of the cytoplasm is observed in part of the cells. A significant decrease in the amount of heterochromatin and a significant enlargement of the perinuclear space are observed in the nuclei of B-lymphocytes of patients of the AID3 group.

On the surface of the karyolema in a group of AID1 ribosome accumulation, which indicates an increase in the rate of protein synthesis is detected. The opposite pattern is observed in patients of the AID2 and AID3 groups. The content of ribosomes on the surface of the karyolema decreased in both study groups compared with the control group.

Patients of the AID1 group visualize the clarity of the tubules of the endoplasmic reticulum, unlike the AID2 and AID3 groups, where the enlargement of the endoplasmic reticulum tanks is markedly increased and a progressive decrease in the content of ribosome-bound ribosomes on its surface is noted.

Some mitochondria of cells in the AID1 group have been found to be swollen, with an enlightened granular matrix, which may indicate the intensity of cell energy metabolism. In patients of group AID2 mitochondria are slightly swollen with the enlightened matrix, limited number of organelles with destroyed crystals is seen. In patients of the AID3 group, the mitochondria are significantly swollen with the enlightened matrix, and many organs of organelles are destroyed.

The ratio of activated B-lymphocytes, as well as the number of free ribosomes in these cells, decreases proportionally in the AID1, AID2, and AID3 groups, respectively.

\section{ELECTRON MICROSCOPY OF THE PHARYNGEAL TONSIL OF ADULTS WITH NON-INFLAMMATORY DISEASES OF THE NOSE AND NPS}

Comparison of the ultramicroscopic picture of $\mathrm{PT}$ patients of the groups AND1, AND2 (Fig. 3) and AND3 revealed signs of decrease in the number and activity of the B-lymphocyte gene apparatus. These cells are of ordinary structure, with a nucleus located on the periphery, whose area decreases in proportion with age. While the amount of heterochromatin in nuclei increases. It should be noted that there is a significant increase in collagen fibers in the intercellular matrix and in the number of fibroblasts that corresponds to sclerotic changes in the organs of the AND3 group.

The granular endoplasmic reticulum of B-lymphocytes in the AND1 group is moderately developed with numerous ribosomes on the surface of the reticulum. Whereas in the AND2 and AND3 groups, the granular endoplasmic reticulum decreases in an area with a significant decrease in ribosomes. In patients of group GNZ1 mitochondria of cells without signs of an increase in energy metabolism, there is a decrease in their number and more significant enlightenment of the organelle matrix in groups AND2 and AND3.

In individuals of groups AND1 and AND2, the number of activated B-lymphocytes is significantly reduced compared to the control group, and in the group of AND3 these cells are practically not observed. 
There is a tendency for a moderate increase in the number of T-lymphocytes in the studied groups AND1, AND2 and AND3 respectively. The nucleus of these cells contains a small amount of heterochromatin, the perinuclear space in places has an expansion. If there is a large number of free ribosomes and mitochondria in the AND1 group, then these elements occur in the AND2 group patients alone or absent in the AND3 group. It should also be noted that there is a gradual decrease in the number of T-lymphocyte plasmalemma invaginations in the AND, AND2 and AND3 groups, respectively, which may indicate a decrease in their activity.

\section{DISCUSSION}

As already noted, data on studies of the incidence of PT hypertrophy in adults are almost absent in the current literature. Only a single description of individual cases of adenoids in adults and even the elderly are known. Yes, M. Nikolaev described two cases of observation of adenoid vegetations in patients 51 and 75 years. In one of them, morphological examination revealed pronounced signs of inflammation - adenoiditis [10]. Another author reported seeing an adenoid patient at the age of 58 [11]. $\mathrm{N}$. Mikhalkin and L.Yakub in their work "Adenoids and Adenoidism in Adults" described the results of a survey of 400 adult patients with ENT diseases. Adenoid vegetations were detected in 57 patients, most patients were aged 2630 years [12].

A. Nihinson in 1952 carried out studies of the nasopharynx in adults on cadaveric material. It revealed the presence of adenoid vegetations in the nasopharynx in 62 of the 95 corpses examined [13]. A. Volkov with co-authors in 1999 reported about 103 adults aged 15 till 66 with adenoiditis [6]. G. Protasevich with co-authors operated on 127 patients aged from 15 to 48 years and found II degree of adenoids in 92 people. In this case, I degree of hypertrophy of adenoids occurred in 22 people, III degree - in 8 , IV degree - in 5 patients [14].

It should be noted that there is also a limited amount of joint research on diseases of the nose and paranasal sinuses with compatible hypertrophy of the pharyngeal tonsil. Thus, in the screening study of adult patients with chronic diseases of the nose and paranasal sinuses, S. Ilyinsky, and other researches found $23.4 \%$ of cases of adenoid vegetation in the examined [15].

L. Baryshevska and others in the study of immunological parameters in adults with adenoiditis found a decrease in cellular and humoral immunity. A decrease in the relative number of T- and B-lymphocytes, as well as a decrease in the number of IgG and SIgA against the background of an increase in the number of IgA and IgM was found [16]. Rosenfeld I.M. found that the pharyngeal tonsil in an adult reduces its activity, but does not completely inhibit its function [17].

V. Bykova and others in their work obtained the results of presence in children working T- and B-zones in the hypertrophied pharyngeal tonsil, which allowed them to be attributed to an actively functioning peripheral or secondary organ of immunity, the main function of which is the induction of the immune response. This has been confirmed by histological and immunohistochemical studies [18].

We have established in the control group age involution of B- and T-lymphocytes in the pharyngeal tonsils, which is characterized by decrease in the number of activated immunocompetent cellular elements and decrease in the activity of intracellular structures. There is a gradual decrease in synthetic and energy processes, accompanied by a decrease in mitochondria and ribosomes in groups CG1 - CG3, respectively. There was also a significant decrease in the number of cells themselves with a predominance of connective tissue elements in the group of persons over 46 years of age.

Ultrastructural changes of the components of $\mathrm{PT}$ in inflammatory diseases of the nose and paranasal sinuses indicate a significant activation of the immune response of competent cells in persons aged 18 to 25 years. In the future, there is an increased activity of B- and T-lymphocytes of the pharyngeal tonsil, especially in patients aged $26-45$ years. The percentage of activated lymphocytes is also significantly reduced along with the increase in ultrastructural changes. Particularly affected are mitochondria, which are involved in the energy supply of cells. Despite the initial low activity of T- and B-lymphocytes in patients of the older age group, activation of lymphoid elements is observed, which is manifested in the decrease in cell number and changes in intracellular structure. Thus, increased activity of lymphoid cells with a predominant increase in T-lymphocytes indicates chronic inflammation, which is more pronounced in patients of middle and older age groups.

In our studies in the AND group, B-lymphocyte activity remained virtually unchanged. However, the activation of the nuclear apparatus in young patients is observed, as evidenced by changes in the amount of heterochromatin. At the same time, the number of T-lymphocytes increases, even in patients of the older age group, which is characteristic of chronic inflammation. Despite the increase in the number of lymphocytes, their intracellular structure is primitive, which characterizes the inability of the cell to complete immune response. Based on the peculiarities of the cell reaction, we can assume the need for drug stimulation of immunogenetic and reduction of the activity of chronic inflammatory response.

Further study of the morphological structure of the pharyngeal tonsil will formulate indications for conservative and surgical treatment of adenoids. Studying the state of the immune system of patients with adenoiditis will help to predict the effectiveness of treatment.

\section{CONCLUSIONS}

1. Electron microscopy of the pharyngeal tonsil in patients of the control group indicates a significant activity of lymphocytic elements and high energy metabolism of cells of this organ. About $25 \%$ of B-lymphocytes are activated. Despite the development of sclerotic changes, which are manifested by an increase in the number of intercellular fibers and fibroblasts, lymphocytic activity 
is observed in patients of groups CG2 and CG3. Part of the lymphocytes is morphologically related to the activated ones, although their numbers decrease significantly with age. Despite this, T-and B-lymphocytes have a developed network of endoplasmic reticulum, the number of bound and free ribosomes is slightly reduced. Thus, it can be assumed that in the elderly, the pharyngeal tonsil contains lymphoid elements capable of an active immune response.

2. The complex of ultrastructural changes of the components of the pharyngeal tonsil in inflammatory diseases of the nose and NPS indicates a significant activation of the immune response of competent cells in individuals aged 18 to 25 years. In the future, there is an increased activity of B- and T-lymphocytes of the pharyngeal tonsil, especially at the age of $26-45$ years. This increases the number of structural changes in cells, which indicates their functional overload. The percentage of activated lymphocytes along with increasing ultrastructural changes is also significantly reduced. Particularly affected are mitochondria, which are involved in the energy supply of cells. Despite the initial low activity of $\mathrm{T}$ - and B-lymphocytes in patients of the older age group, activation of lymphoid elements is observed, which is manifested in the reduction of cell number and changes in intracellular structure. Thus, increased activity of lymphoid cells with a predominant increase in T-lymphocytes indicates chronic inflammation, which is more pronounced in patients of middle and older age groups.

3. In the group of patients with non-inflammatory diseases of the nose and NPS, the activity of B-lymphocytes of the racing tonsils is almost unchanged. At the same time, the number of T-lymphocytes increases, even in patients of the older age group, which is characteristic of chronic inflammation. Despite the increase in the number of lymphocytes, their intracellular structure is primitive, which characterizes the inability of the cell to complete immune response.

\section{REFERENCES}

1. Pereira L., Monyror J., Almeida F.T. et al. Prevalence of adenoid hypertrophy: Asystematic review and meta-analysis. Sleep Med Rev. 2018;38:101-112.

2. Sarma N., Khaund G. A Comparative Study of Radiograph and Nasal Endoscopy in Diagnosis of Hypertrophied Adenoids. Indian J Otolaryngol Head Neck Surg. 2019;71(3):1793-1795.

3. Bowers I., Shermetaro C. Adenoiditis. StatPearls Publishing. 2019. Available at: https://www.ncbi.nlm.nih.gov/books/NBK536931/

4. Zabolotniy D.I. Hypertrophiya lymphadenoidnoi tkaniny glotki [Hypertrophy of the lymphoadenoid tissue of throat]. In: Laiyko AA, Melnikov OF.: Kyiv.Logos. 2009, p. 51. (UA).

5. Smiianov Y.V., Smiianov V.A., Sniehirova I.A. et al. Algorithm of adenoiditis treatment in adults, depending on the pharyngeal tonsil hypertrophy stage. Wiad. Lek. 2018;71(3):564-568.

6. Volkov A.G., Chimicheva E.V., Urakcheeva Ash. Vospaleniye I hypertrophiya glotochnoi mindaliny u vzroslix [Inflammation and hyprtrophy of pharangeal tonsil]. Rossiyskaya rinologiya. 1999;2:4-8 (Ru).

7. Kishuk V.V. Kliniko-imunologichni pidchody do ocinky funkcionalnogo stany pidnebinnich migdalykiv dlya diagnostiki ta licyvannya khvorych na khronichniy tonzilit [Klinical and immunological approaches to functional state of tonsils for diagnostics and treatment of patients for tonsillitis]. Avtoreferat dis. na zdobuttya naukovogo stypenya doc.med. nauk.; spec. 14.01.19. "Otorinolaryngologya". Kyiv. 2001; 35. (UA)

8. Zabolotna D.D. Kliniko-imunologichni osoblivosti diagnostici ta licyvannya khvorych na khronichniy rinit pri patologii pidnebinnich migdalykiv [Klinical and immunological features of diagnosis and treatment of patients for chronic rhinitis accompanied with pathology of tonsil] . Avtoreferat dis. na zdobuttya naukovogo stypenya cand.med. nauk.; spec. 14.01.19. "Otorinolaryngologya". Kyiv. 2002; 20. (UA)

9. Melnikov 0.F., Zabolotniy D.I., KishukV.V. et al. Issledovanie roli nebnich mindalin v formirovanii mestnogo gumoralnogo immuniteta v slizistoy obolochke nosa [Research of the role of pharyngeal tonsil in formation of local humoral in nasal mucosa]. Zhurnal vushnich, nosovich I gorlovich chvorob. 1998:5:69-72. (Ru)

10. Nikolayev MP. Dva sluchaya adenoidnich vegetaciy v pozhilom vozraste [Two cases of adenoid vegetation in elderly people]. Vestnik otorynolaryngologii. 1976;6:99-100. (Ru)

11. Senukov MV. Razrastaniya adenoidnoi tkani v pozhilom vozraste [Growth of the adenoid tissue in old age]. Zhurnal ushnich, nosovich I gorlovich bolezney. 1966;6:70. (Ru)

12. Mikhalkin N.P., Yakub L.I. Adenoidi I adenoidizm u vzroslich [Adenoids in adenoiditis in adults]. Zhurnal ushnich, nosovich I gorlovich bolezney. 1940;12:99-107. (Ru)

13. Nichinson A.G. K vozrastnoi anatomii nosoglotki [To the age anatomy of nasopharynx]. Vestnik otorinolaryngologii. 1952;6:76-77. (Ru)

14. Protasevich G.A., Yashan I.A., Yashan A.I. Adenoidi u vzroslich [Adenoids in adults]. Vestnik otorinolaryngologii. 1999;5:1-13. (Ru)

15. Ilinskiy S.E., Shilenkov 0.0., Mikhailov M.G. et al. Hypertrophiya glotochnoi mindalini u vzroslih I ee vliyaniye na sostoyaniye polosti nosa I okolonosovich pazuch [Hypertrophy of pharyngeal tonsil and its affect on the nose and nasopharynx state]. Rossiyskaya rinologiya. 2006;2:22. (Ru)

16. Barishevskaya L.A., Tarasova N.V., Velicanov A.K. et al. Ostroye vospaleniye glotochnoi mindalini u vzroslih [Severe inflammation of pharyngeal tonsil in adults]. Tezisi XVII siezda otorinolaringologov Rossii. 2006;160-161. (Ru)

17. Rozenfeld I.M. Adenoidniye razrasheniya [Adenoidis growth]. Chirurgicheskiye bolezni nosa, pridatochnih pazuh I nosoglotki. Moskva; 1949, p. 568-580. (Ru)

18. Bikova V.P., Antonova N.A.,YUnusov A.S. etal. Kliniko-morphologicheskiy analiz adenoidnich vegetaciy u detey [Klinical and morphological analysis of adenoid vegetation in children]. Vestnik otorinolaryngologii. 2000;5:9-12. (Ru)

The study was a part of scientific project «Studying of the children and adult's health of the Sumy region population in the context of influence of unfavorable social, ecological and economical factors" (State Registration Number 0101U002098). The study was not financed by any external sources.

\section{ORCID and contributionship:}

Inna A. Plakhtiienko: 0000-0002-4200-8997 B,D,F

Yevhen V. Smiianov: 0000-0003-4996-1550 B,C,F

Vladyslav A. Smiianov: 0000-0002-4240-5968 ${ }^{A, E, F}$

Volodymyr V. Savchenko: ${ }^{E, F}$ 